\title{
O infinitivo flexionado en galego: unha análise variacionista baseada na lingua oral
}

\section{Galician inflected infinitive: a variationist analysis based on oral language}

\author{
Javier Rivas \\ University of Colorado Boulder (Estados Unidos) \\ rivasrod@colorado.edu
}

\author{
Esther L. Brown \\ University of Colorado Boulder (Estados Unidos) \\ brownel@colorado.edu
}

\section{Resumo}

O presente traballo ofrece os resultados da primeira análise variacionista do infinitivo flexionado en galego no contexto das cláusulas adverbiais co obxectivo de identificar a gramática probabilística da dita construción, en contraposición ao infinitivo invariable e ao subxuntivo. Os resultados suxiren que os padróns de uso do infinitivo flexionado están condicionados principalmente polo grao de accesibilidade do referente do suxeito da cláusula adverbial. Canto máis baixa é a accesibilidade do dito suxeito, maior é a posibilidade de que apareza a forma flexionada. Ademais, a análise variacionista amosa que, a medida que aumenta a complexidade sintáctica da cláusula, aumenta tamén a probabilidade de que apareza o subxuntivo. Polo tanto, o uso do infinitivo flexionado está restrinxido a cláusulas cunha complexidade sintáctica reducida. Os resultados están baseados nos datos do CORILGA, un extenso corpus de galego oral dun millón catrocentas mil palabras. Compárase tamén o infinitivo flexionado en galego e portugués en canto á frecuencia e contextos de uso, así como á súa aparición cun suxeito nominativo. A través da análise dos datos dunha lingua pouco estudada (galego), o obxectivo último é contribuír ao coñecemento do infinitivo flexionado, un fenómeno gramatical excepcional nas linguas do mundo.

\section{Palabras chave}

Sintaxe; infinitivo flexionado; linguaxe oral; galego; portugués; método variacionista

\section{Sumario}

1. Introdución. 2. Aproximación tipolóxica ao infinitivo. 3. O infinitivo flexionado en galego. 4. Datos e metodoloxía. 5. Resultados. 5.1. Infinitivo fronte a subxuntivo. 5.2. Infinitivo invariable fronte a infinitivo flexionado. 5.3. Infinitivo flexionado fronte a subxuntivo. 5.4. Resumo dos resultados. 6. Discusión: comparanza entre galego e portugués.
Recibido o 25/02/2020

Aceptado o 01/10/2020

\section{Abstract}

This study reports the results of the first variationist analysis of the Galician inflected infinitive in adverbial clauses. Our objective is to unveil the probabilistic grammar of the inflected infinitive in opposition to both the uninflected infinitive and the subjunctive. Our results reveal that the usage patterns of the inflected infinitive are primarily conditioned by the degree of accessibility of the subject referent of the adverbial clause. The lower the degree of accessibility of the subject, the more likely it is for the infinitive to be inflected. Additionally, our results also suggest that the use of inflected infinitives is restricted to clauses that present a low degree of syntactic complexity. As the syntactic complexity of the clause increases, so does the likelihood for the subjunctive to occur. Our results are based on the data extracted from CORIL$G A$, a large corpus of oral Galician of one million four hundred thousand words. We also compare the frequency of use, occurrence with an expressed subject and contexts of use of inflected infinitives in Galician and Portuguese. By means of the analysis of the data from an under-studied language (Galician), our final goal is to contribute to our knowledge of the inflected infinitive, an exceptional grammatical phenomenon in language.

\section{Key words}

Syntax; inflected infinitive; oral language; Galician; Portuguese; variationist methodology

\section{Sumario}

1. Introduction. 2. A typological approach to infinitives. 3. The Galician inflected infinitive. 4. Data and method. 5. Results. 5.1. Infinitive vs. subjunctive. 5.2. Uninflected infinitive vs. inflected infinitive. 5.3. Inflected infinitive vs. subjunctive. 5.4. Summary of results. 6. Discussion: a comparison between Galician and Portuguese. 


\section{Introdución}

$\mathrm{X}$ UNTO co infinitivo invariable, en galego existe un tipo de infinitivo ao cal se lle engaden desinencias verbais de número e persoa en concordancia co seu suxeito. O dito infinitivo coñécese como infinitivo flexionado (tamén chamado infinitivo conxugado ou infinitivo persoal). Ambos os dous infinitivos, invariable e flexionado, están en variación sintáctica, como se pode ver en (1) e (2) co verbo facer (facer-faceren):

(1) e non endebedaron o Estado para facer iso? (OFDL-CORILGA-BEIRAS$-02-2012)^{1}$

(2) mesmo aproveitan para faceren o seu agosto (OFDL-CORILGA-BEIRAS-02-2012)

Fronte ao infinitivo invariable, que é unha forma recorrente translingüisticamente, o infinitivo flexionado é un fenómeno infrecuente nas linguas do mundo. De todas as linguas en que se manifesta, a que recibiu maior atención na bibliografía é, sen dúbida ningunha, o portugués. Sobre esta lingua existen abundantes traballos dende aproximacións teóricas máis formais (Raposo 1987; Scida 2004; Duarte, Gonçalves \& Santos 2012; Gonçalves, Santos \& Duarte 2014; Fiéis \& Madeira 2017; Sheehan 2018), a aproximacións cognitivas (Soares da Silva 2008; Vesterinen 2011), e baseadas no uso (Schulte 2007; Vanderschueren 2013; Vanderschueren \& Diependaele 2013; Vanderschueren \& De Cuypere 2014). Estes traballos contribúen ao noso cońecemento da construción a través de análises que explican a súa existencia dentro de diferentes marcos teóricos (xenerativista, relacional, cognitivo) e a través de estudos baseados en corpus que identifican os contextos de uso da construción que son recorrentes no discurso.

Dado que o infinitivo flexionado aparece tamén noutras linguas, cómpre analizarmos este fenómeno máis alá do portugués co obxectivo de establecer comparacións interlingüísticas e obter unha visión máis completa desta construción infrecuente dende unha perspectiva translingüística. Nesta liña, o obxecto de estudo deste traballo é o infinitivo flexionado en galego. Baseamos a nosa análise nun corpus de datos do galego oral. Utilizamos o método variacionista para determinar a gramática probabilística do infinitivo flexionado en galego, considerando tanto os contextos de variación entre infinitivo invariable e infinitivo flexionado como os contextos de variación entre infinitivo flexionado e subxuntivo. Antes de pasar á análise, cómpre situarmos as construcións de infinitivo no conxunto de estratexias que empregan as linguas do mundo nas áreas de subordinación substantiva e adverbial para explicar

1. Esta referencia remite á clasificación de textos que se establece no CORILGA (Corpus Oral Informatizado da Lingua Galega). Deste corpus recollemos os datos en que se basea a análise que presentamos neste traballo. Véxase o apartado 4 para unha descrición máis pormenorizada do corpus. 
por que o infinitivo flexionado é unha categoría inusual ou excepcional nas linguas. Ao dito labor dedicamos a seguinte epígrafe.

\section{Aproximación tipolóxica ao infinitivo}

Nas linguas do mundo pódense atopar diferentes estratexias ou padróns tipolóxicos nas áreas da subordinación substantiva (tamén chamada complementación) e adverbial (Givón 2001; Noonan 2007; Dixon 2010). Nalgunhas linguas, a subordinación substantiva e a subordinación adverbial exprésanse a través de cláusulas en modo indicativo que presentan as mesmas características gramaticais ca as cláusulas declarativas dependentes/principais. Nas ditas cláusulas de indicativo, o suxeito aparece en caso nominativo, suxeito e verbo concordan en número e persoa e o verbo presenta variación en canto a tempo e aspecto. En (3) e (4) aparecen exemplificadas respectivamente unha cláusula subordinada substantiva e unha cláusula adverbial en modo indicativo:

(3) Pedro cre que Adela ten que traballar (exemplo inventado)

(4) Chamoume cando eu rematei o exame (exemplo inventado)

Unha segunda estratexia que utilizan as linguas do mundo para expresaren subordinación substantiva e adverbial son as cláusulas en modo subxuntivo. Este tipo de cláusulas tamén ten unha estrutura gramatical similar ás cláusulas declarativas independentes en canto a que o suxeito aparece en caso nominativo e suxeito e verbo concordan en número e persoa. Porén, en contraposición coas cláusulas de indicativo, as cláusulas de subxuntivo caracterízanse por amosar unha variación máis reducida en canto ao tempo e o aspecto. Véxanse os seguintes exemplos en que o galego emprega cláusulas de subxuntivo para a subordinación substantiva (5) e adverbial (6):

(5) Pedro non cre que Adela teña que traballar (exemplo inventado)

(6) Chamarémola cando eu remate o exame (exemplo inventado)

En (5) a forma de subxuntivo teña utilízase tanto para indicar simultaneidade coma posterioridade con respecto á orientación temporal do verbo principal cre. Porén, en (3) a forma ten, aínda que pode utilizarse en galego con valor de futuro (Álvarez \& Xove 2002: 298), está en contraposición coa forma terá, que indica primariamente posterioridade.

Unha terceira estratexia que empregan as linguas do mundo para codificar a subordinación substantiva e adverbial é a construción nominalizada. Como indica Givón (2001: 25), unha construción totalmente nominalizada presenta as seguintes características: 
a) $\mathrm{O}$ verbo convértese nun substantivo.

b) $\mathrm{O}$ verbo adquire as categorías gramaticais típicas do substantivo (e. g., xénero, número).

c) Non hai variación de tempo-modo-aspecto.

d) Pérdese a concordancia entre suxeito e verbo.

e) O suxeito non aparece ou aparece nun caso oblicuo.

f) Poden aparecer determinantes (artigos, demostrativos, posesivos).

g) Os adverbios convértense en adxectivos.

Como indica este autor, a nominalización é unha categoría gradual; existe un contínuum de construcións máis ou menos nominalizadas (Givón 2001: 26). Nunha lingua coma o inglés, no dito contínuum podemos atopar estruturas como as seguintes, de máis a menos nominalizadas:

(7) Contínuum de construcións nominalizadas do inglés: (Givón 2001: 26)

a) Her good knowledge of math helped (substantivo)

b) Her knowing math well helped (xerundio)

c) For her to know math so well helped (infinitivo)

d) She wanted to know math well (infinitivo)

e) Having known math well since high school helped (participio)

f) She should have known math well (participio)

Como se pode ver, neste contínuum de nominalización inclúese o infinitivo. Podemos dicir, xa que logo, que o infinitivo é unha estratexia de nominalización que utilizan as linguas para expresaren subordinadas substantivas e adverbiais.

As cláusulas de infinitivo caracterízanse por amosar ausencia de concordancia suxeito-verbo. De feito, o suxeito do infinitivo non aparece explícito se é correferencial co suxeito do verbo principal. O dito fenómeno coñécese na teoría xenerativista clásica como un caso de equi(valent)-NP-deletion 'supresión da frase nominal equivalente' (Bach 1974), tamén chamado control en modelos máis recentes da teoría (Landau 2001):

(8a) I want to have next weekend off (inglés, exemplo inventado)

(8b) Quero ter a próxima fin de semana libre (exemplo inventado)

(9a) He left the house to put out the fire (inglés, exemplo inventado)

(9b) Saíu da casa para apagar o lume (exemplo inventado)

Se o suxeito do infinitivo non é correferencial co suxeito do verbo principal, existen dúas posibilidades: utilízase unha cláusula en modo subxuntivo, como nos exem- 
plos (10) e (11) do galego, ou ben o suxeito do infinitivo aparece nun caso oblicuo, como nos exemplos (12) e (13) do inglés, equivalentes aos do galego²:

(10) Quero que ela teña a próxima fin de semana libre (exemplo inventado)

(11) Saíu da casa para que apagaran o lume (exemplo inventado)

(12) I want her to have next weekend off (inglés, exemplo inventado)

(13) He left the house for them to put out the fire (inglés, exemplo inventado)

Porén, existen dúas construcións de infinitivo que son excepcionais en canto que non seguen estas tendencias translingüísticas trazadas nos parágrafos anteriores: o infinitivo con suxeito en nominativo e o infinitivo flexionado en concordancia en número e persoa co seu suxeito. Nalgunhas linguas, como español e portugués, o suxeito do infinitivo pode aparecer explícito no caso nominativo (Schulte 2007, 2018; Vanderschueren 2013). Esta construción é máis frecuente en cláusulas adverbiais ca en cláusulas substantivas en ambas as linguas. En (14) e (15) aparecen exemplos en ambas as dúas linguas nunha cláusula temporal:

(14) Ela morreu poucos minutos despois de eu chegar (Schulte 2018: 176)

(15) ...después de preguntarle yo por la ausencia del cuadro (Corpus del español, España ABC [Davies 2002-])

Estes exemplos tamén recollen unha característica da construción na que español e portugués difiren: a posición do suxeito do infinitivo. Mentres que o portugués favorece a anteposición do suxeito ao infinitivo, en espańol o suxeito tende a aparecer despois do infinitivo ${ }^{3}$. Ademais, a construción de infinitivo con suxeito explícito é moito máis frecuente en portugués ca en español.

O infinitivo flexionado en concordancia en número e persoa co seu suxeito é un fenómeno que se pode manifestar de dous xeitos diferentes: nalgunhas linguas como o húngaro (Moreno 1985) e o inglés antigo (Traugott 1992) agrégaselle ao infinitivo unha desinencia nominal, como se pode ver no seguinte exemplo, onde o infinitivo (understandenne) e o seu suxeito (eow) aparecen en caso dativo ${ }^{4}$ :

2. Como se pode ver nos exemplos de (8) a (13), a alternancia entre infinitivo e subxuntivo obsérvase tanto ao nivel da complementación como da subordinación adverbial. Debe terse en conta que a dita alternancia non funciona de maneira totalmente equivalente nos dous contextos sintácticos. Fronte ao que sucede nas cláusulas completivas, nas subordinadas adverbiais a aparición do infinitivo non está restrinxida a casos nos que o seu suxeito é equivalente ao suxeito da cláusula principal, como veremos no desenvolvemento deste traballo.

3. Excepcións a esta tendencia son as variedades de español caribeño, as cales favorecen os suxeitos preverbais (Rivas, Brown \& Cortés-Torres 2018).

4. Nos exemplos (16) e (17) resaltamos o infinitivo flexionado separando a desinencia flexiva da raíz do infinitivo a través dun guión. 
(16) Đis fers is swiðe deoplic eow to understand-enne (inglés antigo, Anderson 1993: 14)

'Este verso é moi profundo para que ti o entendas/para ti entendérelo'

Noutras linguas o infinitivo utiliza desinencias verbais de acordo coa persoa e o número do suxeito. Este fenómeno aparece en portugués, galego, mirandés, sardo e variedades medievais do napolitano e do leonés (Scida 2004: 2). En (17) proporciónase un exemplo do infinitivo flexionado en portugués:

(17) Para aquecer-mos um pouco vamos fazer este pequeno exercício (portugués, Vanderschueren \& Diependaele 2013: 162)

Como xa se mencionou ao comezo deste traballo, outros termos para referirse a este fenómeno son infinitivo persoal ou infinitivo conxugado. Desde un punto de vista tipolóxico, o termo flexionado parece máis adecuado xa que permite recoller as diferentes manifestacións morfolóxicas desta construción segundo a lingua 5 . $\mathrm{O}$ concepto de flexión emprégase para referírmonos tanto ao nome (declinación) coma ao verbo (conxugación). Isto permite relacionar o infinitivo flexionado cuxos morfemas de número e persoa son desinencias verbais (como no galego), co infinitivo flexionado en que os morfemas de número e persoa coinciden con desinencias nominais (como no húngaro). A pesar destas diferenzas morfolóxicas, ambos os tipos presentan importantes concomitancias sintácticas no que respecta ao uso (Moreno 1985: 460-462).

\section{O infinitivo flexionado en galego}

En galego, como en portugués, o infinitivo flexionado presenta desinencias verbais específicas na segunda persoa de singular (ser-es) e nas persoas de plural (ser-mos, ser-des e ser-en). As formas da primeira e terceira persoa de singular son sincréticas co infinitivo invariable (ser). O infinitivo flexionado pode aparecer con suxeito expreso e, se o dito suxeito é un pronome, este aparecerá en caso nominativo, como se pode ver en (18):

(18) esa neniña que mamá trouxo pra ti xogares (MECI-CORILGA-AMARINHEIRA-01-2007)

Como sinalan Álvarez e Xove (2002: 307), "o infinitivo flexionado non é estritamente obrigado en ningún caso”. Isto quere dicir que nos contextos en que aparece

5. Para unha perspectiva diferente, véxanse García Gondar (1978: 11-13) e Asaka (1983). 
o infinitivo flexionado pode tamén aparecer o infinitivo invariable. Estamos, xa que logo, ante un caso de variable sintáctica, é dicir, dúas construcións (infinitivo invariable e infinitivo flexionado) cuxas distincións gramaticais e semánticas se neutralizan no discurso (Sankoff 1988: 153) para se converteren en formas equivalentes dende o punto de vista comunicativo (Croft 2010: 42) á hora de verbalizar a mesma situación.

O infinitivo flexionado do galego aparece descrito nas gramáticas de referencia da lingua (Álvarez, Regueira \& Monteagudo 1986; Costas Casas et al. 1988; Álvarez \& Xove 2002; Freixeiro Mato 2006), nas cales tamén se inclúen, nalgúns casos, pautas para o seu uso (véxase amais Frexeiro Mato 1999). O infinitivo flexionado galego, polo seu carácter excepcional dende unha perspectiva translingüística, foi así mesmo obxecto de estudo das gramáticas formais (Longa 1994, 1999; Parafita Couto 2004; Sheehan, Schäfer \& Parafita Couto 2019). Estas análises están baseadas na intuición ou en experimentos de produción controlada para determinar xuízos de gramaticalidade. Finalmente, existen aproximacións ao infinitivo flexionado dende a lingüística de corpus (García Gondar 1978; Asaka 1984; Jasengers \& Vanderschueren 2010a, 2010b; Vázquez Diéguez 2012; Gerards 2015). Os resultados destes traballos están baseados principalmente en textos escritos (linguaxe literaria e científica).

No presente traballo utilizaremos os datos tomados dun extenso corpus de galego oral co obxectivo de proporcionarmos unha análise baseada no uso dos infinitivos flexionados en galego. A través do método variacionista (Labov 1994, Walker 2010, Tagliamonte 2012), identificaremos os factores lingüísticos que restrinxen a aparición do infinitivo flexionado no galego oral. A dita construción estudarase en oposición non soamente ao infinitivo invariable senón tamén ao subxuntivo. Os resultados das análises cuantitativas permitirannos desvelar a gramática probabilística do infinitivo flexionado do galego. Tendo en conta os achados dos estudos baseados en corpus do infinitivo flexionado en portugués (Schulte 2007; Vanderschueren 2013; Vanderschueren \& Diependaele 2013; Vanderschueren \& De Cuypere 2014), presentaremos unha análise contrastiva deste fenómeno gramatical. Deste xeito, o presente traballo pretende contribuír ao coñecemento do infinitivo flexionado como construción excepcional dende un punto de vista translingüístico.

\section{Datos e metodoloxía}

Os datos en que se basea este estudo están tomados do Corpus Oral Informatizado da Lingua Galega (CORILGA). Este corpus consta de aproximadamente un millón catrocentas mil palabras de galego oral procedentes de gravacións feitas entre os anos sesenta e a actualidade con falantes de diferentes idades e xéneros. O corpus inclúe diferentes rexistros (linguaxe estándar e literaria, formal e informal, rural e urbana), así como conversas, entrevistas, discursos e conferencias. 
Deste corpus extraemos todos os exemplos nos que o infinitivo aparece cunha desinencia verbal de persoa (segunda de singular, primeira de plural, segunda de plural ou terceira de plural $)^{6}$. En total, atopamos 148 exemplos do infinitivo flexionado no corpus. Como se pode ver, trátase dunha construción de baixa frecuencia (105 exemplos por millón de palabras). De todos estes exemplos, o $76 \%(\mathrm{~N}=112)$ aparece precedido de nexos adverbiais, precisamente os contextos nos cales se favorece o infinitivo flexionado en galego segundo os achados de estudos anteriores (García Gondar 1978: 140141; Asaka 1984: 3; Gerards 2015: 7; Sheehan, Schäfer \& Parafita Couto 2019: 9).

$\mathrm{Na}$ nosa análise incluímos os nexos adverbiais que presentan unha porcentaxe de aparición do infinitivo flexionado igual ou máis alta ca o 5\% en relación co uso do infinitivo invariable. A través deste procedemento, eliminamos da análise variacionista aqueles nexos adverbiais cuxas porcentaxes de aparición con infinitivo flexionado son menores do 5\%, dado que nestes casos a variación é case inexistente e a súa inclusión no contexto variable reduciría a importancia das restricións de uso de cada unha das variantes. Seguindo este método, incluímos na análise cuantitativa os seguintes tipos de construcións adverbiais:

a) Cláusulas finais introducidas por para, pra ou pa

b) Cláusulas temporais encabezadas por antes de e ao

c) Cláusulas modais con sen

d) Cláusulas causais introducidas mediante por

Os resultados deste estudo están baseados no 52\% (N=77) dos exemplos do infinitivo flexionado que atopamos no corpus.

De acordo co principio de responsabilidade (Labov 1972), amais dos exemplos con infinitivo flexionado, forman tamén parte da análise aquelas construcións en que, podendo ter aparecido o infinitivo flexionado, o falante utiliza o infinitivo invariable. A dita variación aparece limitada á segunda persoa de singular e ás persoas de plural, dado que na primeira e terceira persoa de singular hai coincidencia formal entre o infinitivo flexionado e o invariable.

As cláusulas finais con para/pra/pa, as cláusulas temporais con antes e as cláusulas con sen poden tamén expresarse a través dunha cláusula conxugada en modo subxuntivo, como se pode ver en (19). Por tanto, incluímos tamén este tipo de cláusulas no envoltorio da variación/contexto variable ${ }^{7}$ :

6. Non hai exemplos de primeira e terceira persoa de singular porque, como xa se indicou anteriormente, non presentan marcas flexivas específicas.

7. Un dos avaliadores externos pregunta se o subxuntivo é realmente unha variante desta variable sintáctica e alega dous motivos para cuestionar esta decisión metodolóxica:

a) o infinitivo e o subxuntivo expresan ás veces significados diferentes. Este avaliador sinala que en portugués Escondi-me antes de ele me ver non ten o significado de propósito ou finalidade que se asocia coa construción equivalente en subxuntivo Escondi-me antes que ele me visse, a cal se pode 
(19) a xente que lle iba levare o lińo pa que elas fixesen a tela (OIED-RURAGO-MOS-02-1993)

Tendo en conta os resultados de traballos anteriores sobre o infinitivo flexionado en portugués e galego (xa citados anteriormente), manexamos a hipótese de que a estratexia a través da cal se expresan as cláusulas adverbiais estará condicionada por dous mecanismos cognitivos:

1. A accesibilidade do referente do suxeito (Ariel 2001; Vesterinen 2011): xeralmente nunha interacción lingüística mencionamos diferentes participantes a través das funcións sintácticas (suxeito, obxecto directo, obxecto indirecto). Isto provoca que en moitos contextos haxa diferentes participantes en competición pola referencia. Ariel (2001) argumenta que a expresión lingüística dos constituíntes da cláusula está condicionada polo grao de accesibilidade que ten o oínte ao seu referente, é dicir, canto máis accesibilidade, menos expresión lingüística ${ }^{8}$ precisa o receptor da mensaxe para a súa identificación.

2. O grao de complexidade sintáctica: Dentro da lingüística existen diferentes aproximacións ao concepto de complexidade sintáctica. Nos procesos de adquisición de primeira lingua, a complexidade sintáctica está relacionada coa idade de adquisición dunha determinada estrutura; canto máis tarde a adquire o individuo, máis complexa é (Clark 2016). Na gramática formal (e.g., Jakubowicz 2011), a complexidade sintáctica asociouse co número de operacións de movemento necesarias para construír unha cláusula, sendo máis complexa aquela cláusula que precisa de máis operacións. Ademais, neste mesmo marco teórico, tamén se relaciona a complexidade sintáctica cunha concepción dos parámetros como xerarquías nas que hai opcións menos marcadas, cunha única estrutura sintáctica (e polo tanto máis simples sintacticamente falando), e

interpretar como Escondi-me com a intenção de que ele não me visse. En realidade, o infinitivo pode ter tamén ese mesmo valor en exemplos como antes de comer un ovo eles inda primeiro retorcían a gorxa a seis ou sete (OIED-RUR-CHEN-ORDES-34-1965). Ademais, ese significado de propósito/intención non parece formar parte de significado básico da conxunción senón que é en realidade unha inferencia invitada polo contexto (Traugott \& Dasher 2002: 16).

b) o subxuntivo esixe un suxeito diferente ao do verbo principal, é dicir, non é posible dicir Tirei os sapatos antes que (eu) entrasse em casa porque eu é tanto o suxeito de tirei como de entrasse. En realidade, aínda que fóra do seu contexto discursivo estas construcións poidan parecer estrañas ou incluso agramaticais, atópanse no corpus que manexamos: antes de que do baile saias has de molla-la camisa (OIED-RUR-CHEN-ORDES-11-1965), os cans teñen que estar ben fortalecidos pa que: traballen, pa que teñan forza (OIED-RUR-AGO-MOS-04-1993).

8. Dentro dos mecanismos de expresión lingüística, podemos incluír os seguintes (de menos a máis expresión): concordancia > clíticos $>$ pronomes persoais tónicos $>$ frases nominais léxicas. 
opcións máis marcadas con dúas ou máis estruturas sintácticas e, xa que logo, máis complexas (vid. Biberauer et al. 2014) ${ }^{9}$. Por outra banda, no seo da gramática cognitiva, Rohdenburg (1996: 151), tomando como base o concepto de complexidade do procesamento que Hawkins $(1990,1992)$ utiliza nos seus traballos sobre a tipoloxía da orde de palabras, formula o principio de complexidade, que establece que "in the case of more or less explicit grammatical options the more explicit one(s) will tend to be favored in cognitively more complex environments". Este principio de complexidade explica a distribución dunha grande variedade de fenómenos gramaticais en competición (vid. Rohdenburg 2020). No que respecta á subordinación adverbial obxecto de estudo deste traballo, entendemos grao de complexidade sintáctica na liña que establece Rohdenburg (1995: 368) para a complementación clausal, é dicir, canto máis complexa é unha construción sintáctica, maior será a probabilidade de que presente unha estrutura oracional.

Tendo en conta estes dous mecanismos cognitivos, establecemos as seguintes hipóteses:

1. Canto máis grande sexa o grao de accesibilidade do referente en función de suxeito da cláusula adverbial, maior será a probabilidade de que o infinitivo sexa invariable.

2. Canto máis complexa sexa a cláusula dende un punto de vista sintáctico, máis probable é a necesidade de utilizar unha cláusula subordinada en modo subxuntivo.

Para levarmos a cabo a análise cuantitativa, operacionalizamos estes dous mecanismos cognitivos a través dunha serie de factores lingüísticos que nos permiten probar estas hipóteses no que respecta ás restricións de uso das diferentes estratexias lingüísticas de que dispón o galego para codificar cláusulas adverbiais. Ao operacionalizarmos estes mecanismos cognitivos, convertémolos en mensurables a través de observacións empíricas. A accesibilidade cognitiva operacionalízase mediante os seguintes factores: cambio de referencia, distancia referencial e posición da cláusula adverbial:

9. Biberauer et al. (2014: 105-106) proporcionan o seguinte exemplo: para a complementación dos verbos do tipo believe 'crer' e persuade 'convencer', o inglés dispón de tres estruturas sintácticas: unha cláusula conxugada (I believe that he is tired 'creo que está canso'), un infinitivo con marcador de caso excepcional (I believe him to be tired 'creo que está canso') e un infinitivo sen marcador de caso excepcional (I persuaded him to come with me 'convencino de que viñera comigo'). Outras linguas como o francés (ou o galego) utilizan soamente dúas destas estruturas (a cláusula conxugada: creo que ten razón e o infinitivo sen marcador de caso excepcional: creo ter razón). Finalmente, en linguas coma o grego a cláusula conxugada é a única estrutura que aparece na complementación destes verbos. 
a) Cambio de referencia: o referente do suxeito da cláusula adverbial será máis accesible para o receptor cando coincide co do suxeito da cláusula principal (mesma referencia) que cando é diferente (cambio de referencia). Neste último caso, a presenza dun referente distinto na cláusula principal aumenta o número de competidores pola referencia (Ariel 2001: 13). Xa que logo, a nosa hipótese é que en contextos de cambio de referencia aumentará o número de infinitivos flexionados (véxase tamén Álvarez \& Xove 2002: 307). Para determinar a relevancia desta hipótese nos datos, cada un dos exemplos codifícase como mesma referencia ou cambio de referencia, dependendo de se o suxeito da cláusula principal é o mesmo ou distinto. A continuación, presentamos un exemplo de cada unha das opcións:

(20) sei que para un desempregado non é un consolo saber que faremos todo o posible para derrotar o paro (MEDE-CORILGA-NUNHEZFEIJOOVAZQUEZ-07-2012)

(21) as galegas e os galegos non nos elexiron para facer o fácil (MEDE-CORILGA-NUNHEZFEIJOO-VAZQUEZ-07-2012)

No exemplo (20), o suxeito do infinitivo derrotar é o mesmo que o suxeito de faremos (nós), así que este exemplo codificouse como mesma referencia. Pola contra, en (21) o suxeito de facer é nós, mentres que o suxeito da cláusula anterior é as galegas e os galegos, polo que este exemplo se codificou como cambio de referencia.

b) Distancia referencial: canto máis grande é a distancia entre os referentes de dous suxeitos consecutivos na cadea discursiva, menor é a accesibilidade do suxeito da cláusula adverbial (Ariel 2001: 37). Nesta liña, a nosa hipótese é que haberá unha correlación entre a distancia entre os referentes dos suxeitos e a presenza dun infinitivo flexionado. Canto maior sexa a distancia entre os referentes dos suxeitos, meirande a posibilidade de que o infinitivo da cláusula adverbial estea flexionado. Esta hipótese xa se manexa en traballos anteriores sobre o portugués (Vanderschueren \& De Cuypere 2014: 158) e o galego (García Gondar 1978: 158; Álvarez \& Xove 2002: 307).

Polo tanto, codificamos a distancia entre o suxeito da cláusula adverbial e o suxeito da cláusula principal en número de palabras, independentemente da forma de expresión dos ditos suxeitos (frases nominais léxicas, formas pronominais ou concordancia verbal). Isto dános como resultado a distancia entre referentes accesibles en número de palabras ${ }^{10}$. Como mostra, véxase o exemplo (22), en que a distancia

10. No reconto de palabras, a conxunción que (paralpralpa que, antes de que, sen que), a cal introduce as cláusulas en subxuntivo, considérase parte do nexo introdutor para equiparar en número de palabras este 
entre o suxeito do infinitivo descansarmos e o suxeito da cláusula anterior, que aparece expresado a través da concordancia verbal (poñemos), son sete palabras:

(22) aí poñemos a mesa e ai uns asentos pra descansarmos das aventuras (MEDO-CORILGA-OESPIRITODOBOSQUE-01-2008)

$\mathrm{Na}$ análise cuantitativa, que se describe no apartado seguinte, a distancia referencial considérase unha variable continua.

c) Posición da cláusula adverbial: a cláusula adverbial pode aparecer antes ou despois da cláusula principal. García Gondar (1978: 158) e Álvarez e Xove (2002: 303) indican que as cláusulas adverbiais que aparecen antes da cláusula principal favorecen o uso do infinitivo flexionado. Dende unha perspectiva psicolingüística, Diessel (2005) argumenta que as cláusulas adverbiais son máis fáciles de procesar se aparecen despois da cláusula principal ca antes. Ademais, as cláusulas adverbiais tamén presentan diferentes funcións discursivas segundo a posición que ocupan con respecto á cláusula principal (Thompson 1985; Ford 1993; Verstraete 2004). Por exemplo, mentres que as cláusulas finais que aparecen despois da cláusula principal indican cal é o obxectivo do evento que se expresa naquela, as cláusulas finais antepostas á cláusula principal teñen unha función máis ampla, relacionada coa organización do discurso. Por tanto, o suxeito das cláusulas adverbiais que aparecen antes da cláusula principal será menos accesible que o suxeito das cláusulas adverbiais que aparecen despois da cláusula principal. Dado que os suxeitos daquelas cláusulas son menos accesibles, favorecerán o uso de infinitivo flexionado.

O segundo mecanismo cognitivo que utilizamos para explicar a diferenza entre infinitivo invariable, infinitivo flexionado e subxuntivo é a complexidade sintáctica. Determinamos o grao de complexidade sintáctica da cláusula adverbial a través dunha serie de factores lingüísticos que permiten establecer o seu grao de verbalidade (Vanderschueren 2013; Vanderschueren \& De Cuypere 2014). Os ditos factores, citados a continuación, foron seleccionados por unha parte porque nos permiten operacionalizar este mecanismo cognitivo para a análise cuantitativa e por outra porque os traballos de corpus tanto do galego (García Gondar 1978; Asaka 1984; Jansegers e Vanderschueren 2010a, 2010b; Vázquez Diéguez 2012; Gerards 2015) como do portugués (Schulte 2007; Vanderschueren 2013; Vanderschueren \& Diependaele 2013; Vanderschueren \& De Cuypere 2014) os identifican como condicionantes da variación entre infinitivo invariable e infinitivo flexionado:

nexo co que introduce as cláusulas de infinitivo (paralpralpa, antes de, sen). 
a) Polaridade: afirmativa (para ter) vs. negativa (para non ter)

b) Clítico reflexivo: presente (para aproveitarse) vs. ausente (para aproveitar)

c) Perífrase verbal: presente (antes de ir traballar) vs. ausente (antes de traballar)

d) Aktionsart: verbos estativos (ser/estar) vs. outros

A presenza na cláusula adverbial de polaridade negativa, un clítico reflexivo, unha perífrase verbal e/ou un proceso verbal eventivo aumenta a verbalidade da cláusula (Vanderschueren \& De Cuypere 2014: 159-161). Dado que estes factores contribúen a facer máis explícito o carácter oracional da construción, a sua presenza tamén aumenta a complexidade sintáctica tal e como é concebida por Rohdenburg (1995, $1996,2020)^{11}$.

Para desvelarmos a gramática probabilística do infinitivo flexionado en galego, levamos a cabo tres análises cuantitativas diferentes. Na primeira das análises cuantitativas, utilizamos como variable dependente a oposición subxuntivo versus infinitivo (flexionado ou invariable). Nesta análise inclúense aquelas cláusulas adverbiais que se expresan ben a través dun infinitivo ben a través dun subxuntivo: cláusulas finais con paralpralpa, cláusulas temporais con antes de e cláusulas modais con sen. Incluímos na análise todas as persoas de singular e plural. Os resultados están baseados en todos os exemplos $(\mathrm{N}=596)$ que aparecen na sección de galego oral formal do corpus.

A segunda análise cuantitativa ten como variable dependente a oposición infinitivo flexionado vs. infinitivo invariable. Inclúense nesta análise todos os nexos adverbiais obxecto de estudo neste traballo: paralparalpa, antes de, sen, ao e por. Soamente se teñen en conta para a análise os exemplos en que o verbo aparece en segunda persoa de singular e nas tres persoas do plural, por seren estes os contextos en que se pode observar a alternancia entre infinitivo invariable e infinitivo flexionado. Considéranse todos os exemplos $(\mathrm{N}=504)$ que aparecen no corpus (tanto formal como informal).

Finalmente, a oposición infinitivo flexionado vs. subxuntivo é a variable dependente da terceira análise cuantitativa. Nesta análise inclúense aqueles nexos adverbiais (paralpralpa, antes de, sen) que poden aparecer cun infinitivo ou un subxuntivo. Os datos manexados engloban os exemplos en que o verbo aparece na segunda persoa de singular ou nas formas de plural. Extráense todos os exemplos dos corpus formal e informal. Os resultados están baseados en 137 exemplos.

11. Fronte aos outros factores, a Aktionsart verbal é máis de natureza semántica que sintáctica. Porén, as características semánticas dos verbos estativos ser e estar teñen tamén repercusións no nivel sintáctico. En contraposición aos outros verbos, que teñen significado referencial (Dixon 2010: 100), ser e estar presentan un significado relacional, dado que actúan como enlaces ou nexos de unión entre o suxeito e o predicado (nominal) da oración. Xa que logo, as construccións sintácticas en que aparecen afástanse da estrutura oracional prototípica en que o verbo codifica un evento que determina cales son os participantes da oración. 
Para as análises cuantitativas, utilizamos un modelo linear xeneralizado mixto a través do paquete estatístico $R$ ( $R$ Core Team 2019). Ademais dos factores lingüísticos mencionados anteriormente, incluímos o falante como factor aleatorio. Na epígrafe seguinte resumimos os resultados destas análises.

\section{Resultados}

\subsection{Infinitivo fronte a subxuntivo}

Nesta primeira sección, presentamos os resultados da primeira análise cuantitativa, cuxo obxectivo é determinar que factores lingüísticos favorecen o uso do subxuntivo fronte ao infinitivo (flexionado ou invariable) no corpus oral formal. Como se pode ver no Cadro 1, aínda que as cláusulas adverbiais do galego poden aparecer tanto en infinitivo como en subxuntivo, existe unha tendencia moi marcada no corpus - nun $82 \%$ dos exemplos — a expresar as ditas cláusulas a través do infinitivo.

\begin{tabular}{lcc}
\hline \multicolumn{1}{c}{ Cláusulas adverbiais } & $\mathrm{N}$ & $\%$ \\
\hline infinitivo & 488 & 82 \\
subxuntivo & 108 & 18 \\
total & 596 & 100 \\
\hline
\end{tabular}

Cadro $1 . \%$ de uso do infinitivo fronte ao subxuntivo

Así mesmo, se desagregamos os datos de acordo co tipo de cláusula adverbial, atopamos unha preponderancia do infinitivo con todas elas, como se observa no Cadro 2, sen que haxa diferenzas significativas entre elas:

\begin{tabular}{lcc}
\hline \multicolumn{1}{c}{ Tipo de cláusula adverbial } & infinitivo & subxuntivo \\
\hline paralpralpa & $81 \%$ & $19 \%$ \\
antes de & $77 \%$ & $23 \%$ \\
sen & $91 \%$ & $9 \%$ \\
\hline
\end{tabular}

Cadro 2. \% de infinitivo fronte ao subxuntivo segundo tipo de cláusula adverbial

Para identificar que factores lingüísticos predín de maneira significativa a presenza dunha cláusula de subxuntivo, sometemos os datos a unha análise variacionista utilizando R. Este programa permítenos examinar a contribución á expresión do subxuntivo nos datos de cada un dos factores lingüísticos que se utilizan para a análise (cambio de referencia, distancia referencial, posición da cláusula adverbial, 
polaridade, clítico reflexivo, perífrase verbal e Aktionsart). O mellor modelo mixto que identifica $\mathrm{R}$ resúmese no Cadro 3:

\begin{tabular}{lccc}
\hline \multicolumn{1}{c}{ Factor lingüístico } & Estimado & Erro estándar & $\mathrm{p}$ \\
\hline Cambio de referencia: si & 2,76 & 0,372 & 0,000 \\
Distancia & 0,01 & 0,019 & n.s. \\
Polaridade: negativa & 1,467 & 0,565 & 0,001 \\
Clítico reflexivo: si & 1,849 & 0,427 & 0,000 \\
Perífrase verbal: si & 1,526 & 0,375 & 0,001 \\
Aktionsart: estativo & 1,133 & 0.477 & 0,01 \\
\hline
\end{tabular}

Cadro 3. Factores que predín o uso do subxuntivo fronte ao infinitivo ( $\mathrm{N}=596)$

Como se pode ver no Cadro 3, coa excepción da distancia referencial, todos os factores lingüísticos que se consideraron na análise condicionan de maneira significativa a presenza do subxuntivo fronte ao infinitivo nas cláusulas adverbiais. $\mathrm{O}$ grao de complexidade sintáctica da cláusula determina o uso do subxuntivo fronte ao infinitivo no galego oral formal. As construcións con polaridade negativa, cun clítico reflexivo e/ou cunha perífrase verbal favorecen significativamente o uso do subxuntivo. A única excepción é a Aktionsart do verbo. Esperaríase que os verbos estativos desfavorecesen o uso do subxuntivo porque presentan un grao de verbalidade máis baixa que os verbos eventivos. Porén, os resultados reflicten tendencias opostas á hipótese. Así mesmo, a accesibilidade do referente en función de suxeito da cláusula adverbial tamén condiciona o uso do subxuntivo fronte ao infinitivo nestes datos. Cando o suxeito da cláusula adverbial ten un referente diferente ao suxeito da cláusula principal, prefírese o subxuntivo.

\subsection{Infinitivo invariable fronte a infinitivo flexionado}

Nesta segunda sección de resultados, o obxecto de estudo é a oposición entre infinitivo invariable e infinitivo flexionado. Ambos están en variación sintáctica na segunda persoa de singular e nas formas de plural. Nestes contextos, como se pode ver no Cadro 4, o infinitivo invariable é máis frecuente ca o infinitivo flexionado, o cal aparece soamente no $15 \%$ dos exemplos.

\begin{tabular}{lcc}
\hline \multicolumn{1}{c}{ Cláusulas adverbiais de infinitivo } & $\mathrm{N}$ & $\%$ \\
\hline infinitivo invariable & 427 & 85 \\
infinitivo flexionado & 77 & 15 \\
total & 596 & 100 \\
\hline
\end{tabular}

Cadro $4 . \%$ de infinitivo invariable fronte a infinitivo flexionado 
Ao desagregarmos os datos segundo tipo de cláusula adverbial (Cadro 5), obsérvase que ao é o único nexo adverbial que presenta unha porcentaxe máis alta de infinitivos flexionados que de infinitivos invariables. De feito, a dita porcentaxe é significativamente máis alta $\left(\mathrm{p}=0.000, \chi^{2}=201,5899\right)$. Por outra banda, sen é o nexo que máis desfavorece o uso de infinitivo flexionado, con só un $5 \%$ de aparición. Esta diferenza de uso é tamén estatisticamente significativa $\left(\mathrm{p}=0.002, \chi^{2}=9.55612\right)$ con respecto aos outros nexos.

\begin{tabular}{lcc}
\hline \multicolumn{1}{c}{ Tipo de cláusula adverbial de infinitivo } & invariable & flexionado \\
\hline paralpralpa & $85 \%$ & $15 \%$ \\
antes de & $83 \%$ & $17 \%$ \\
ao & $38 \%$ & $62 \%$ \\
por & $81 \%$ & $19 \%$ \\
sen & $95 \%$ & $5 \%$ \\
\hline
\end{tabular}

Cadro 5. \% de infinitivo invariable e infinitivo flexionado segundo tipo de cláusula adverbial

No Cadro 6 aparece o resumo do mellor modelo mixto que proporcionou $\mathrm{R}$ ao sometermos estes datos a unha análise estatística:

\begin{tabular}{lccc}
\hline \multicolumn{1}{c}{ Factor lingüístico } & Estimado & Erro estándar & $\mathrm{p}$ \\
\hline Cambio de referencia: si & 1,302 & 1,27 & 0,001 \\
Distancia & 0,036 & 0,048 & n.s. \\
Posición da cláusula adverbial: antes & 1,184 & 0,668 & 0,05 \\
Aktionsart: estativo & 2,934 & 1,037 & 0,01 \\
Cambio de referencia X Distancia & 0,069 & 0,069 & n.s. \\
\hline
\end{tabular}

Cadro 6. Factores que predín o uso do infinitivo flexionado fronte ao invariable $(\mathrm{N}=504)$

De todos os factores lingüísticos, soamente tres resultaron ser estatisticamente significativos á hora de predicir a presenza dun infinitivo flexionado nas cláusulas adverbiais do galego: cambio de referencia do suxeito da cláusula adverbial, anteposición da cláusula adverbial á cláusula principal e presenza dun verbo estativo (ser/estar) na cláusula adverbial. A distancia referencial non resultou significativa nin tampouco un factor adicional que incluímos na análise para determinar se existía unha interacción entre o cambio de referencia e a distancia referencial. Tendo en conta estes resultados, podemos concluír que, a medida que diminúe a accesibilidade do referente suxeito, tamén aumenta a probabilidade de que o infinitivo apareza flexionado. Chegamos a esta conclusión porque o infinitivo flexionado aparece favorecido significativamente fronte ao infinitivo invariable en contextos de cambio de referencia e en cláusulas adverbiais antepostas á cláusula principal. 
A complexidade sintáctica da cláusula adverbial non parece desempeñar un papel relevante na escolla entre o infinitivo invariable e o flexionado nestes datos. De feito, o único factor que resulta significativo con respecto a este mecanismo cognitivo é a Aktionsart do verbo da cláusula adverbial. Porén, os resultados que aparecen no Cadro 6 con respecto a este factor van en dirección contraria á predita pola nosa hipótese: os verbos estativos favorecen de maneira estatisticamente significativa o uso do infinitivo flexionado. Dado que os procesos verbais non estativos aumentan a verbalidade, estes resultados non apoian a existencia dunha correlación entre maior complexidade sintática e maior presenza dun infinitivo flexionado.

\subsection{Infinitivo flexionado fronte a subxuntivo}

Neste último apartado de resultados, presentamos os achados no que respecta ao uso do infinitivo flexionado fronte ao subxuntivo. Como xa se indicou, para esta análise consideramos soamente as formas de segunda persoa de singular e as de plural, así como as cláusulas adverbiais que se poden expresar en infinitivo e subxuntivo. Nos datos de galego oral que manexamos para esta análise, obsérvase unha lixeira preferencia polo subxuntivo nestes casos, cun $57 \%$ dos exemplos:

\begin{tabular}{lcc}
\hline \multicolumn{1}{c}{ Cláusulas adverbiais } & $\mathrm{N}$ & $\%$ \\
\hline infinitivo flexionado & 59 & 43 \\
subxuntivo & 78 & 57 \\
total & 137 & 100 \\
\hline
\end{tabular}

Cadro 7. \% de infinitivo flexionado fronte a subxuntivo

Tendencias similares pódense ver se dividimos os datos segundo o nexo adverbial, coma no Cadro 8. Tanto as cláusulas finais como as cláusulas temporais con antes de aparecen máis a miúdo en subxuntivo que en infinitivo, mentres que, no caso das cláusulas con sen, o infinitivo flexionado é máis frecuente ca o subxuntivo. Porén, as diferenzas entre estes nexos adverbiais (paralpra/pa, antes de e sen) non acadan significatividade estatística.

\begin{tabular}{lcc}
\hline \multicolumn{1}{c}{ Tipo de cláusula adverbial } & infinitivo flexionado & subxuntivo \\
\hline paralpralpa & $43 \%$ & $57 \%$ \\
antes de & $33 \%$ & $67 \%$ \\
sen & $71 \%$ & $29 \%$ \\
\hline
\end{tabular}

Cadro 8. \% de infinitivos flexionados fronte a subxuntivos segundo tipo de cláusula adverbial 
Do mesmo xeito que nas anteriores, o obxectivo da análise cuantitativa foi atopar os factores lingüísticos que condicionan a aparición do infinitivo flexionado fronte ao subxuntivo no galego oral. O Cadro 9 resume o mellor modelo mixto que obtivemos na análise cuantitativa:

\begin{tabular}{lccc}
\hline \multicolumn{1}{c}{ Factor lingüístico } & Estimado & Erro estándar & $\mathrm{p}$ \\
\hline Cambio de referencia: si & $-4,629$ & 2,19 & 0,01 \\
Posición da cláusula adverbial: antes & $-2,929$ & 1.989 & n.s. \\
Polaridade: negativa & $-4,783$ & 3,862 & n.s. \\
Clítico reflexivo: si & $-8,255$ & 3,925 & 0,01 \\
Perífrase verbal: si & $-5,569$ & 3,115 & 0,05 \\
Aktionsart: estativo & $-0,237$ & 1,834 & n.s. \\
\hline
\end{tabular}

Cadro 9. Factores que predín o uso do infinitivo flexionado fronte ao subxuntivo $(\mathrm{N}=137)$

Os factores que resultaron significativos nesta análise son tres: cambio de referencia, presenza de clítico reflexivo e presenza de perífrase verbal. Nestes tres contextos, o infinitivo flexionado é significativamente menos probable ca o subxuntivo, como indican os valores negativos na columna de estimado. As cláusulas adverbiais antepostas ás cláusulas principais, a polaridade negativa e os verbos estativos ser e estar, aínda que teñen a mesma dirección de efecto, non acadan significatividade estatística.

Tendo en conta estes resultados, podemos concluír que a medida que aumenta a complexidade sintáctica da cláusula, diminúe a probabilidade de que apareza o infinitivo flexionado e, xa que logo, aumenta a probabilidade de que se use o subxuntivo. Isto aparece corroborado na análise cuantitativa polo feito de que as construcións con clítico reflexivo e con perífrase verbal desfavorecen o uso de infinitivo flexionado fronte ao subxuntivo de xeito estatisticamente significativo. Por outra parte, cando a accesibilidade do referente do suxeito da cláusula adverbial é reducida, diminúe a probabilidade de que apareza o infinitivo flexionado e aumenta, consecuentemente, o uso do subxuntivo. Esta análise vese corroborada porque, cando hai un cambio de referencia, o infinitivo flexionado vese desfavorecido de maneira significativa sobre o subxuntivo.

\subsection{Resumo dos resultados}

As cláusulas adverbiais do galego pódense expresar a través de tres mecanismos diferentes: infinitivo invariable, infinitivo flexionado e subxuntivo. A elección destes mecanismos vén condicionada por dous factores cognitivos: o grao de accesibilidade do referente en función de suxeito e o grao de complexidade sintáctica da cláusula adverbial. A accesibilidade cognitiva do referente do suxeito condiciona a elección 
entre infinitivo invariable e infinitivo flexionado, sendo este último favorecido en contextos en que o seu suxeito é menos accesible para o receptor da mensaxe. Nas cláusulas adverbiais en que o infinitivo e o subxuntivo aparecen en variación sintáctica (finais con paralpralpa, temporais con antes de e modais con sen), o subxuntivo tamén se asocia con contextos en que o referente do suxeito da cláusula adverbial ten baixa accesibilidade para o interlocutor. Xa que logo, os falantes de galego contan con dúas formas de expresión para codificaren os referentes dos suxeitos menos accesibles: o infinitivo flexionado ou o subxuntivo. Por outra parte, a complexidade sintáctica da cláusula adverbial condiciona a elección entre infinitivo e subxuntivo en galego. A medida que medra o grao de verbalidade da cláusula, aumenta tamén a probabilidade de que apareza o subxuntivo. Porén, cos verbos estativos (ser/estar), obsérvase unha tendencia oposta á hipótese xa que, fronte aos verbos eventivos, desfavorecen o infinitivo invariable.

\section{Discusión: comparanza entre galego e portugués}

Os contextos de uso do infinitivo flexionado en galego e portugués son moi semellantes, (vid. García Gondar 1978: 59; Jansegers \& Vanderschueren 2010a: 416; Gerards 2015: 1; entre outros). As aproximacións diacrónicas a este fenómeno suxiren que o infinitivo flexionado xurdiu nas cláusulas adverbiais, máis concretamente nas cláusulas con peralpara/por. Estes son os contextos en que a dita construción aparece máis frecuentemente nos textos históricos (García Gondar 1978; Wireback 1994; Martins 2001; Harris 2013). Na actualidade, as cláusulas adverbiais aínda seguen a ser o contexto no cal o infinitivo flexionado aparece máis a miúdo en ambas as linguas (Jansegers \& Vanderschueren 2010a: 418). No que respecta ao galego vimos que, no corpus oral en que se basean os resultados deste traballo, as cláusulas adverbiais dan conta do $76 \%$ dos casos de infinitivo flexionado.

Dentro das cláusulas adverbiais, algúns tipos parecen favorecer o uso do infinitivo flexionado fronte a outros. Os resultados porcentuais que achega o presente traballo suxiren a seguinte xerarquía de conectores adverbiais, sendo os que aparecen á esquerda os que máis favorecen o uso do infinitivo flexionado nos datos: ao > por $>$ antes de > para > sen. Así mesmo, como xa vimos, existe unha diferenza estatisticamente significativa no que respecta á aparición do infinitivo flexionado con ao fronte aos outros conectores. De igual maneira, sen desfavorece o uso de infinitivo flexionado fronte ao infinitivo invariable de tal xeito que acada significatividade estatística cando se compara co resto dos conectores. Nun traballo anterior, Jansegers e Vanderschueren (2010a: 434) propońen a seguinte xerarquía de conectores adverbiais, tendo en conta os usos do infinitivo flexionado que atopan en traducións literarias ( $\mathrm{N}=59$ ): antes de $>$ para $>$ ao $>$ despois de $>$ ata $>$ a pesar de $>$ sen. 
Aínda que se poden atopar nestes resultados algunhas diverxencias, probablemente debidas a diferenzas entre os estudos no que respecta á cantidade e tipo de datos analizados, tamén podemos extraer algunhas tendencias comúns. Por exemplo, sen é o conector menos habitual en combinación con infinitivo flexionado. Pola contra, as cláusulas temporais parecen ser o contexto en que o infinitivo flexionado se ve máis favorecido no galego actual. De feito, xa García Gondar (1978: 142) sinala que, dende as cláusulas finais e causais en que xurdiu o infinitivo flexionado, esténdese hoxe en día o seu uso especialmente ás cláusulas temporais ${ }^{12}$.

Os resultados dos estudos sobre o portugués baseados no uso (Vanderschueren 2013; Vanderschueren \& Diependaele 2013 e Vanderschueren \& De Cuypere 2014) suxiren que a accesibilidade cognitiva do referente en función de suxeito da cláusula adverbial e o grao de verbalidade/complexidade sintáctica da cláusula desempeñan un papel fundamental á hora de determinar as restricións de uso do infinitivo flexionado fronte ao infinitivo invariable nesta lingua. Como xa vimos na sección anterior, a expresión da cláusula adverbial en galego tamén se ve condicionada por estes dous mesmos mecanismos cognitivos, a través dos cales explicamos os contextos de uso recorrentes do infinitivo invariable, o infinitivo flexionado e o subxuntivo nas cláusulas adverbiais do galego oral.

Porén, existen tamén diferenzas importantes entre ambas as linguas no que respecta ao uso do infinitivo flexionado. Se o suxeito da cláusula adverbial é diferente ao suxeito do verbo principal (contextos de cambio de referencia), o infinitivo flexionado é practicamente obrigado en portugués (Vanderschueren 2013: 140). En galego, o cambio de referencia favorece o uso do infinitivo flexionado sobre o infinitivo invariable, pero nestes contextos o infinitivo flexionado compite con outra estratexia: a cláusula adverbial en subxuntivo ${ }^{13}$. De feito, os resultados da análise cuantitativa que comparan o uso de infinitivo flexionado fronte ao subxuntivo en galego indican que o cambio de referencia do suxeito da cláusula adverbial favorece o uso do subxuntivo fronte ao infinitivo nesta lingua.

Así mesmo, en galego a diferenza entre infinitivo flexionado e invariable está condicionada principalmente polo grao de accesibilidade do referente en función de

12. No caso do portugués, segundo os resultados de Vanderschueren e De Cuypere (2014) antes de, depois de e por favorecen o uso do infinitivo flexionado, mentres que para, sem e ao desfavoréceno. Debe terse en conta que estes datos soamente inclúen construcións nas cales o suxeito do infinitivo é correferencial co suxeito da cláusula principal. Por este motivo, resulta difícil establecer comparacións entre ambas as linguas.

13. En portugués é tamén posible o uso do subxuntivo nestes contextos (Vesterinen 2011: 4; Vanderschueren 2013: 126). Aínda que non dispońemos de datos cuantitativos que determinen a frecuencia de uso da construción con subxuntivo fronte á construción con infinitivo flexionado en cláusulas adverbiais do portugués, todo parece indicar que nesta lingua o subxuntivo é moito menos frecuente que en galego (vid. por exemplo os resultados que proporciona Schulte (2007: 181) do uso da construción de infinitivo con suxeito expreso fronte ao subxuntivo). 
suxeito. Canto máis accesible é o suxeito da cláusula adverbial menos probable é o infinitivo flexionado. En portugués, ademais do grao de accesibilidade, a aparición do infinitivo flexionado está tamén restrinxida polo grao de verbalidade da cláusula adverbial. Canto máis características verbais presenta a cláusula adverbial, maior é a posibilidade de que o infinitivo apareza flexionado (Vanderschueren \& De Cuypere 2014: 171). Pola contra, en galego, a medida que aumenta o grao de verbalidade/ complexidade sintáctica da cláusula adverbial, medra tamén a probabilidade de que o falante escolla o subxuntivo para codificar a dita cláusula.

Un dos factores lingüísticos que utilizamos para operacionalizar o concepto de complexidade sintáctica, a Aktionsart, deu resultados inesperados. Os verbos estativos, aínda sendo menos "verbais" ca os verbos eventivos, favoreceron o uso do subxuntivo fronte ao infinitivo (\$5.1) e o uso do infinitivo flexionado fronte ao infinitivo invariable $(\$ 5.2)$. Vanderschueren e De Cuypere (2014) atopan resultados semellantes nunha análise baseada no uso do infinitivo flexionado en portugués. Estes autores suxiren que a presenza do infinitivo flexionado con verbos estativos podería ter un efecto compensatorio "as a formal clue in order to underline the verbal status of the infinitive" (Vanderschueren \& De Cuypere 2014: 170). Do mesmo xeito que algunhas linguas utilizan un marcador diferencial para algúns obxectos directos non prototípicos (humanos e/ou definidos), o infinitivo flexionado con ser e estar funciona como un marcador diferencial de verbalidade.

Como xa vimos na epígrafe anterior, as porcentaxes de uso do infinitivo flexionado en galego son moi baixas (15\% nestes datos). Se as comparamos coas do portugués, nesta última lingua son significativamente máis altas. Vanderschueren e De Cuypere (2014: 162) indican que o 51\% dos seus exemplos aparece cun infinitivo flexionado, e esta cifra non inclúe os casos nos cales hai un cambio de referencia entre o suxeito da cláusula adverbial e o suxeito da cláusula principal, contexto en que, como xa vimos, o infinitivo flexionado é a norma en portugués. Esta diferenza no que respecta aos índices de uso do infinitivo flexionado entre as dúas linguas puidera ser en parte debida á influencia que tivo o español no desenvolvemento do galego, o cal puido contribuír a un menor uso da forma flexionada en contextos en que os suxeitos de ambas as cláusulas son correferenciais e ao uso da cláusula de subxuntivo en contextos nos que hai un cambio de referencia no suxeito da cláusula adverbial (García Gondar 1978: 143-144; Vázquez Diéguez 2012: 127).

Un dos contextos en que galego e portugués seguen camiños claramente diferentes é na expresión do suxeito en construcións de infinitivo. Mentres que o infinitivo en portugués vai frecuentemente acompañado dun suxeito - $28 \%$ dos casos nos datos de Jansegers e Vanderschueren (2010a: 419), e máis do 33\% nos datos de Schulte (2018: 177) — en galego aparece xeralmente sen suxeito. García Gondar (1978: 150) soamente atopa un $9 \%$ de suxeitos expresos en textos literarios e un 11\% en textos dialectais, e aínda aparece unha porcentaxe máis baixa de suxeitos expresos (3\%) no corpus de traducións literarias que manexan Jansegers e Vanderschueren (2010a: 419). 
Nesta mesma liña, dos 504 exemplos do noso corpus nos cales é posible a variación infinitivo flexionado fronte a infinitivo invariable, atopamos soamente un 3\% ( $\mathrm{N}=18)$ de exemplos de infinitivo con suxeito expreso. Fronte ao portugués, lingua en que o suxeito tende a aparecer anteposto ao infinitivo, en galego a maioría dos suxeitos ( $72 \%$ $\mathrm{N}=13$ ) está posposto ao infinitivo. Ademais, aínda que na bibliografía anterior (e.g., Freixeiro Mato 2006: 397) se indica que o infinitivo flexionado é obrigatorio cando o seu suxeito aparece explícito, esta afirmación non se ve corroborada nos nosos datos, é dicir, a presenza dun suxeito expreso non comporta necesariamente a flexión do infinitivo. De feito, o $67 \%$ dos exemplos con suxeito expreso aparece cun infinitivo invariable, como se amosa en (23):

\section{(23) Traían comida para comer eles (OIED-RUR-CHEN-BUEU-04-1967)}

No que respecta á porcentaxe de uso de suxeitos con infinitivo e á posición que estes suxeitos acostuman a ocupar, o galego afástase do portugués e achégase ao español. Baseándose en datos de variedades peninsulares, Schulte (2018: 185) sinala que os suxeitos dos infinitivos nesta lingua son moi infrecuentes e tenden a aparecer pospostos ao infinitivo. Ademais, en galego a porcentaxe de suxeitos expresos é significativamente máis alta $(\chi 2=9,354886, \mathrm{p}=0,002)$ nas cláusulas de subxuntivo ca nas cláusulas cun infinitivo flexionado. Todos estes resultados suxiren que os falantes de galego poden estar interpretando a expresión do suxeito e a flexión do infinitivo como dous mecanismos alternativos para codificar aqueles participantes suxeito que presentan un grao de accesibilidade baixo para o receptor da mensaxe. Noutras palabras, a función cognitiva do infinitivo flexionado é semellante á función cognitiva da expresión do suxeito naquelas linguas, coma é o caso do galego, en que o suxeito, ao estar expresado no verbo a través da concordancia, pode non aparecer explícito na mensaxe (Brown \& Rivas 2019: 11).

As análises cuantitativas que se efectuaron neste traballo permiten determinar os patróns de uso do infinitivo flexionado en galego en contraposición ao infinitivo invariable e ao subxuntivo. No ámbito das cláusulas adverbiais, os contextos de uso do infinitivo flexionado no galego actual son máis restrinxidos ca en portugués. As porcentaxes de uso do infinitivo flexionado en galego son significativamente máis baixas e, fronte ao portugués, o infinitivo flexionado xeralmente non se combina cun suxeito expreso. En galego, o infinitivo flexionado vese favorecido en contextos en que o grao de accesibilidade cognitiva do referente do suxeito da cláusula adverbial é baixo e nas cláusulas que presentan unha complexidade sintáctica reducida; a medida que aumenta a complexidade sintáctica da cláusula, preferirase tamén o uso do subxuntivo. 


\section{Agradecementos}

Un dos autores recibiu unha bolsa do College of Arts and Sciences da Universidade de Colorado para realizar unha estadía de investigación no Instituto da Lingua Galega no verán de 2019. Estamos moi agradecidos á Universidade pola axuda financeira e ao Instituto pola cálida acollida de todos os seus integrantes e por compartiren connosco o CORILGA, sen o cal este traballo non tería sido posible. Unha versión preliminar deste estudo foi presentada no 7th Lusophone and Hispanic Linguistics Symposium (Universidade de Wisconsin, Milwaukee) en novembro de 2019. Moitas grazas aos asistentes polas proveitosas preguntas e comentarios que suscitou a presentación así como a Oliva Díaz Lastra polas súas acertadas suxestións á versión inicial deste traballo. Finalmente, queremos expresar o noso agradecemento aos revisores externos desta revista pola lectura atenta e a avaliación construtiva que fixeron do noso traballo. 


\section{Referencias bibliográficas}

Álvarez, Rosario, Xosé Luís Regueira \& Henrique Monteagudo. 1986. Gramática galega. Vigo: Galaxia.

Álvarez, Rosario \& Xosé Xove. 2002. Gramática da lingua galega. Vigo: Galaxia.

Anderson, John. 1993. Parameters of syntactic change: a notional view. En Charles Johns (ed.), Historical linguistics. Problems and perspectives. 1-42. Londres / Nova York: Routledge.

Ariel, Mira. 2001. Accessibility theory: An overview. En Ted J. M. Sanders, Joost Schilperoord \& Wilbert Spooren (eds.), Text representation: Linguistic and psycholinguistic aspects. 29-87. Amsterdam / Philadelphia: John Benjamins. https://doi.org/10.1075/hcp.8.04ari

Asaka, Takekazu. 1983. En torno a la denominación del infinitivo personal. Lingüistica hispánica 6, 43-53.

Asaka, Takekazu. 1984. Empleos del infinitivo personal en gallego moderno. Lingüistica hispánica 7, $1-21$.

Bach, Emmon. 1974. Syntactic theory. New York: Holt, Rinehart \& Winston.

Biberauer, Theresa, Anders Holmberg, Ian Roberts \& Michelle Sheehan. 2014. Complexity in comparative syntax: The view from modern parametric theory. En Frederick Newmeyer \& Laurel Preston (eds.), Measuring grammatical complexity. 103-127. Oxford: Oxford University Press. http://dx.doi.org/10.1093/acprof:oso/9780199685301.003.0006

Brown, Esther \& Javier Rivas. 2019. Bringing purported black sheep into the fold: Galician inflected infinitives and Spanish pre-infinitival nominative subjects. Languages 4/40. http://dx.doi. org/10.3390/languages 4020040

Clark, Eve V. 2016. First language acquisition. $3^{\text {a }}$ edn. Cambridge: Cambridge University Press.

Costa Casas, Xoán Xosé, M.a dos Anxos González Refoxo, César Carlos Morán Fraga \& Xoán Carlos Rábade Castińeira. 1988. Nova gramática para a aprendizaxe da lingua. A Coruña: Vía Láctea.

Croft, William. 2010. The origins of grammaticalization in the verbalization of experience. Linguistics 48/1, 1-48. https://doi.org/10.1515/ling.2010.001

Davies, Mark. 2002-. Corpus del español (100 million words, 1200s-1900s). http://www.corpusdelespanol.org (15/09/2020).

Diessel, Holger. 2005. Competing motivations for the ordering of main and adverbial clauses. Linguistics 43, 449-470. https://doi.org/10.1515/ling.2005.43.3.449

Dixon, Robert M. W. 2010. Basic linguistic theory, 2 vols. Oxford: Oxford University Press.

Duarte, Inês, Anabela Gonçalves \& Ana Lúcia Santos. 2012. Infinitivo flexionado, independência temporal e controlo. En A. Costa, C. Flores \& N. Alexandre (eds.), Textos selecionados. XXVII encontro nacional da Associaçâo Portuguesa de Linguística. 217-234. Lisboa: APL.

Fiéis, Alexandra \& Ana María Lavadinho Madeira. 2017. The Portuguese inflected infinitive across varieties. En Pilar Barbosa, Maria da Conceição Paiva \& Celeste Rodrigues (eds.), Studies on variation in Portuguese. 279-299. Amsterdam/Philadelphia: John Benjamins. https://doi.org/10.1075/ ihll.14.12fie

Ford, Cecilia E. 1993. Grammar in interaction: Adverbial clauses in American English conversations. Cambridge: Cambridge University Press. https://doi.org/10.1017/CBO9780511554278 
Freixeiro Mato, Xosé Ramón. 1999. Sobre os usos do infinitivo flexionado e do futuro do subxuntivo no galego moderno. En Rosario Álvarez Blanco \& Dolores Vilavedra Fernández (eds.), Cinguidos por unha arela común: Homenaxe ó profesor Xesús Alonso Montero, vol. 1. Semblanza e creación; Lingua; Historia, cultura e sociedade. 389-416. Universidade de Santiago de Compostela: Servizo de Publicacións.

Freixeiro Mato, Xosé Ramón. 2006. Gramática da lingua galega II. Morfosintaxe. 2a end. Vigo: A Nosa Terra.

García Gondar, Francisco. 1978. O infinitivo conxugado en galego. Universidade de Santiago de Compostela: Servizo de Publicacións.

Gerards, David Paul. 2015. O infinitivo conxugado galego: Signo indexical e ato identitário. En Benjamin Meisnitzer \& Yvonne Hendrichs (eds.), Sprache und Identität im lusophonen Raum. Stuttgart: Ibidem.

Givón, Talmy. 2001. Syntax. An introduction, 2 vols. Amsterdam / Philadelphia: John Benjamins. https://doi.org/10.1075/z.syn1

Gonçalves, Anabela, Ana Lúcia Santos \& Duarte, Inês. 2014. (Pseudo-) inflected infinitives and control as Agree. En Karen Lahousse \& Stefania Marzo (eds.), Selected papers from 'Going Romance' Leuven 2012. 161-180. Amsterdam: John Benjamins. https://doi.org/10.1075/rllt.6.08gon

Harris, Michael J. 2013. The origin of Portuguese inflected infinitive through a corpus análisis. En Jennifer Cabrelli Amaro, Gillian Lord, Ana de Prada Pérez \& Jessi Elana Aaron (eds.), Selected proceedings of the 16th Hispanic Linguistics Symposium. 303-311. Somerville, MA: Cascadilla Proceedings Project.

Hawkins, John. 1990. A parsing theory of word order universals. Linguistic inquiry 21, 223-261.

Hawkins, John. 1992. Syntactic weight versus information structure in word order variation. En Joachim Jacobs (ed.), Infromationsstruktur und Grammatik. 196-219. Opladen: Westdeutscher Verlag. https://doi.org/10.1007/978-3-663-12176-3_7

Jakubowicz, Celia. 2011. Measuring derivational complexity: New evidence from typically developing and SLI learners of L1 French. Lingua 121/3, 339-351. https://doi.org/10.1016/j.lingua.2010.10.006

Jansegers, Marlies \& Clara Vanderschueren. 2010a. El infinitivo flexionado gallego: ¿entre portugués y castellano? Revue de linguistique romane 74/295-296, 415-441.

Jansegers, Marlies \& Clara Vanderschueren. 2010b. La vitalidad del infinitivo flexionado gallego. En Pablo Cano López, Soraya Cortiñas Ansoar, Beatriz Dieste Quiroga, Isabel Fernández López \& Luz Zas Varela (eds.), XXXIX Simposio internacional de la Sociedad Española de Lingüistica. 1-4 febrero 2010. 33. Santiago de Compostela: Universidade de Santiago de Compostela.

Labov, William. 1972. Sociolinguistic patterns. Philadelphia: Univ. of Pennsylvania Press.

Labov, William. 1994. Principles of linguistic change, vol. 1. Internal factors. Oxford: Blackwell.

Landau, Idan. 2001. Elements of control: Structure and meaning of infinitival constructions. Dordrecht: Kluwer.

Longa Martínez, Víctor M. 1994. The Galician inflected infinitive and the theory of UG. Catalan working papers in linguistics 4, 23-44.

Longa Martínez, Víctor M. 1999. Teoría da optimalidade e ordenación das restriccións universais: presentación e tratamento dos infinitivos conxugados. En Rosario Álvarez / Dolores Vilavedra (eds.), 
Cinguidos por unha arela común: homenaxe ó profesor Xesús Alonso Montero, vol. 1. Semblanza e creación; Lingua; Historia, cultura e sociedade. 533-550. Universidade de Santiago de Compostela: Servizo de Publicacións.

Martins, Ana M. 2001. On the origin of the Portuguese inflected infinitive: A new perspective on an enduring debate. En Laurel J. Brinton (ed.), Historical linguistics 1999. Selected papers from the 14th conference on historical linguistics. 207-222. Amsterdam/Philadelphia: John Benjamins. https://doi.org/10.1075/cilt.215.15mar

Moreno, Juan Carlos. 1985. O infinitivo flexionado em galego e em húngaro: um estudo contrastivo. Agália 4, 457-462.

Noonan, Michael. 2007. Complementation. En Timothy Shopen (ed.), Language typology and syntactic description, vol. 2. Complex constructions. $2^{\text {a }}$ edn. 52-150. Cambridge: Cambridge University Press. https://doi.org/10.1017/CBO9780511619434.002

Parafita Couto, María del Carmen. 2004. Agreement and Focus in Galician Inflected Infinitives. Kansas working papers in linguistics 27, 66-91. https://doi.org/10.17161/KWPL.1808.1244

R Core Team. 2019. A language and environment for statistical computing. R Foundation for Statistical Computing, Vienna, Austria. http://www.R-project.org/ (18/06/2019).

Raposo, Eduardo. 1987. Case theory and the Infl-to-Comp: The inflected infinitive in European Portuguese. Linguistic inquiry 18, 85-109.

Rivas, Javier, Esther Brown \& Mayra Cortés-Torres. 2018. Variable subject pronominal expression in non-finite clauses: implications for variant patterns and emergent contexts. Lingua 215, 27-39. https://doi.org/10.1016/j.lingua.2018.09.004

Rohdenburg, Günter. 1995. On the replacement of finite complement clauses by infinitives in English, English studies 76/4, 367-388. https://doi.org/10.1080/00138389508598980

Rohdenburg, Günter. 1996. Cognitive complexity and increased grammatical explicitness in English. Cognitive linguistics 7/2, 149-182. https://doi.org/10.1515/cogl.1996.7.2.149

Rohdenburg, Günter. 2020. The complexity principle at work with rival prepositions. English language and linguistics 24(4), 769-800. https://doi.org/10.1017/S1360674319000327

Sankoff, David. 1988. Sociolinguistics and syntactic variation. En Frederick Newmeyer (ed.), Linguistics: The Cambridge survey, volume 4. Language: The socio-cultural context. 140-161. Cambridge: Cambridge University Press. https://doi.org/10.1017/CBO9780511620577.009

Scida, Emily. 2004. The inflected infinitive in Romance languages. Nova York: Routledge Taylor \& Francis Group. https://doi.org/10.4324/9780203488768

Schulte, Kim. 2007. Prepositional infinitives in Romance. A usage-based approach to syntactic change. New York: Peter Lang.

Schulte, Kim. 2018. On the position of overt subjects in infinitival clauses in Spanish and Portuguese. Pragmatic, semantic and frequency-based motivations. En Miriam Bouzouita, Ioanna Sitaridou \& Enrique Pato (eds.), Studies in Historical Ibero-Romance Morpho-Syntax. 173-194. Amsterdam / Philadelpia: John Benjamins. https://doi.org/10.1075/ihll.16.08sch

Sheehan, Michelle. 2018. Control of inflected infinitives in European Portuguese. En Anabella Gonçalves \& Ana Lúcia Santos (eds.), Complement clauses in Portuguese: Syntax and acquisition. 2958. Amsterdam: John Benjamins. https://doi.org/10.1075/ihll.17.02she 
Sheehan, Michelle, Maretin Schäfer \& Maria Carmen Parafita Couto. 2019. Crowdsourcing and Minority Languages: The Case of Galician Inflected Infinitives. Frontiers in Psychology 10, 1157. https://doi.org/10.3389/fpsyg.2019.01157

Soares da Silva, Augusto. 2008. The Portuguese inflected infinitive and its conceptual basis. En Barbara Lewandowksa-Tomaszczyk (ed.), Asymmetric events. 227-243. Amsterdam / Philadelphia: John Benjamins. https://doi.org/10.1075/celcr.11.15sil

Tagliamonte, Sali A. 2012. Variationist sociolinguistics. Change, observation, interpretation. Malden, MA / Oxford: Wiley-Blackwell.

Thompson, Sandra. 1985. Grammar and written discourse: Initial vs. final purpose clauses in English. Text 5/1-2, 55-84. https://doi.org/10.1515/text.1.1985.5.1-2.55

Traugott, Elizabeth C. 1992. Syntax. En Richard Hogg (ed.), The Cambridge history of the English language, vol. 1. The beginnings to 1066. 168-289. Cambridge: Cambridge Univ. Press. https:// doi.org/10.1017/CHOL9780521264747.005

Traugott, Elizabeth C. \& Richard B. Dasher. 2002. Regularity in semantic change. Cambridge: Cambridge University Press. https://doi.org/10.1017/CBO9780511486500

Vanderschueren, Clara. 2013. Infinitivo y sujeto en portugués y español. Un estudio empírico de los infinitivos adverbiales con sujeto explícito. Berlin / Boston: Walter de Gruyter. https://doi. org/10.1515/9783110307733

Vanderschueren, Clara \& Kevin Diependaele. 2013. The Portuguese inflected infinitive: An empirical approach. Corpus linguistics and linguistic theory 9/1, 161-186. https://doi.org/10.1515/ cllt-2013-0013

Vanderschueren, Clara \& Ludovic De Cuypere. 2014. The inflected/non-inflected infinitive alternation in Portuguese adverbial clauses. A corpus analysis. Language sciences 41, 153-174. https:// doi.org/10.1016/j.langsci.2013.08.016

Vázquez Diéguez, Ignacio. 2012. O infinitivo (conxugado) galego e portugués e a súas correspondencias en español. Estudos de lingüistica galega 4, 107-130.

Verstraete, Jean-Christophe. 2004. Initial and final position for adverbial clauses in English: the constructional basis of the discursive and syntactic differences. Linguistics 42/4, 819-853. https://doi. org/10.1515/ling.2004.027

Vesterinen, Rainer. 2011. A cognitive approach to adverbial subordination in European Portuguese: The infinitive, the clitic pronoun se and finite verb forms. Newcastle upon Tyne: Cambridge Scholars Publishing.

Walker, James. 2010. Variation in linguistic systems. London: Routledge.

Wireback, Kenneth J. 1994. The origin of the Portuguese inflected infinitive. Hispania 77/3, 544-552. https://doi.org/10.2307/344992 